\title{
COMMUNICATION IN THE MULTICULTURAL BUSINESS CONTEXT: UAE
}

\author{
Viola Gjylbegaj ${ }^{1}$ and Osama Jararaa ${ }^{2^{*}}$ \\ ${ }^{1}$ Assist. Prof. Dr., Abu Dhabi University, United Arab Emirates, viola.gjylbegaj@adu.ac.ae \\ ${ }^{2}$ Adjuct. Prof., Abu Dhabi University, United Arab Emirates, o.jararaa-adjunct@adu.ac.ae \\ ${ }^{*}$ Corresponding author
}

\begin{abstract}
Communication is fundamental in business, because business is a collaborative activity. When business negotiators come from cultures with different rules, communication problems may arise. The diversity among business cultures can frequently lead to confusion, misunderstandings, and failures in cross-cultural commercial endeavours. Thus, developing effective business communication skills for a globalized economy is not a simple matter. In this paper will be analysed some common cross-cultural issues for those entrepreneurs developing relationships with individuals or businesses from different cultural backgrounds: Not understanding how formality, hierarchy and timing can affect business. These things have a tremendous impact on negotiations and decision-making. Business often takes longer with different cultures and countries. Many cultures are more team-focused or "we" oriented. These can really impact the business style. In this paper will be examined the case of the United Arab Emirates that is known to be a multicultural country.
\end{abstract}

Keywords: Communication, multicultural, business, UAE.

\section{INTRODUCTION}

Internationalization, trans-border trade and cross cultural business are all terms that have been coined over the past decade(s) to reflect the reality of the world economy. The UAE is the best result of this modernity and growth, but growth and success in today's global economy depend on being able to work internationally, particularly in the UAE where more than 200 nationalities live together. The business environment has increasingly expanded outside single nations or regions of the world to encompass many differing countries (Sims 2009). Understanding the globalization of business practices is an important area and researchers and academics have been studying the subject of business in multicultural settings for decades. Researchers in different fields, therefore professionals working in multicultural environment have emphasized the importance of knowledge of different cultures and they agree that globalization has brought about the growing trend to communicate with people from different cultural backgrounds. In the past, there have been a lot of problems 
in many countries that were not used on having a multicultural environment and unfortunately they still have a lot of problems. The European countries are still struggling in finding a way of communication with the immigrants of Syria, Albania, Romania, etc. They think that the problems come from the fact that these nationalities speak a different language, but they need to understand that the biggest problem is culture differences. A greater understanding of differing nations and cultures leads to more positive interactions (Lin, 1999) and more successful business relationships (Palazzo, 2002). Different cultures have differing values, perceptions and philosophies. As a result, certain ideas may have very different connotations for people having different cultural backgrounds. Different cultures may have different rules and norms and favour different means of business communication. Cultural differences cause communication problems in every business interaction. The purpose of the present paper is to investigate business communication features of people with different cultural backgrounds in the UAE, which is known for its cultural diversity. Its nationals represent only $15 \%$ of the population, with expatriates comprising the other $85 \%$. There are more than 200 nationalities living in UAE. The majority of them, with more than $50 \%$, come from South Asia (India, Pakistan, Nepal, Bangladesh, Sri Lanka), the second biggest group of expatriates come from the Arab Countries (Palestine, Jordan, Lebanon, Egypt), and The European and the Americans are in lower number. With all these different nationalities and cultures living in a small country like the UAE, where you will find them working together in different organizations, problems of communication may rise up. At the root of the argument is the hypothesis that there is an altering in communication rules and norms between these people. We communicate the way we do because we are raised in a particular culture and learn its language, rules, and norms.

\subsection{Research questions}

\section{Theoretical background}

Globalization is a term that provokes strong reactions, positive or negative but globalization is praised for the new opportunities it brings. (Ellwood 2001, Robertson 1992). Globalization has created more and more multinational companies all over the world, including the UAE where it is normal to see Italian, American, British companies. The phenomena have been considered a promising means to link individuals with different backgrounds and experiences and have attracted the interests of researchers. Consequently, globalization has produced workforce with the diverse cultural backgrounds at the same workplace and/or business encounters who have to work at an international level. Cultures are a different level of logical analysis from the individual members of cultures. Cultures do not talk to each other, individuals do. According to Samovar and Porter (1991: 10) intercultural communication occurs whenever a message is produced by a member of one culture for consumption by a member of another culture, a message must be understood. Because of cultural differences in these kinds of contacts, the potential for misunderstanding and disagreement is great. To reduce this risk, it is important to study intercultural business communication and the UAE is the best country that can show how the culture differences influence communication.

\section{Aim and method}

This article examines the aspects relating to understanding culture and cultural differences and focuses on the relationship between culture and business in the multicultural environment in the UAE. It is emphasized that the intercultural aspect of business communication has been playing an important role in the contemporary business contacts and contact alone does not lead to understanding. In multicultural context you have to be able to make informed choices, to decide to what extent to use your own communication style. Current research is based on a survey conducted in 2017 at two multinational companies in Abu Dhabi, UAE. Data were gathered by a questionnaire entitled "Communication in the multicultural Business context, UAE". The sample was random and taken from business actors across all levels of positions.

\section{Questionnaire}

The questionnaire tests the hypothesis that cultural differences in business communication are attributable to the misunderstanding of communication. We examine specific instances of business encounters' communication to assess how the process of communication about culture affected interaction in business situations. The questionnaire used in this research consisted of 14 questions. The first part of the questionnaire measured assess to cultural differences and its effect on communication. The second part of the questionnaire asked for information on cross-cultural understanding and on sufficient cultural awareness.

\section{The participants}

200 questionnaires have been sent to employees working at two multinational companies and 200 questionnaires have been sent back. Informants who had significant international business experience had been selected. As for the nationality the majority of them are expatriates, only few are local. Potentially 
respondents were sought from the researcher's own network and 'snowballed' by participants passing on the questionnaires to colleagues.

Table 1

\begin{tabular}{|c|c|}
\hline Nationality & Participant \\
\hline Jordanian & 44 \\
\hline Indian & 42 \\
\hline Egyptian & 34 \\
\hline Lebanese & 21 \\
\hline Palestinian & 15 \\
\hline American & 11 \\
\hline Local & 21 \\
\hline European & 8 \\
\hline Filipino & 4 \\
\hline
\end{tabular}

Most of them had all high level of education (University or College Degree, Master, Doctorates). The majority of the participants are between 30 and 40 years old. 15 participants were less than 30 and only 3 of them were older than 51 . When it comes to the period of time living in the UAE, most of them answered between 2 to 5 years, only 4 respondents answered more than 5 years, and 20 of them were in the country since less than 1 year and the locals were born in the UAE.

It is supposed by the researcher that there are no language problems during the business communication. Every participant speaks more than one language apart from their mother tongue. The working language is English but occasionally the Arab speakers use Arabic language as well, particularly with clients who are Arabs and their English is not perfect. Informants' spoken English is high and its fluency has been required before applying for the job in question. Usually, Arabic language is not required but it's an advantage.

\section{FINDINGS}

One of the most heatedly debated issues in the literature on interactions involving participants from various cultural backgrounds is undoubtedly that of Intercultural Dialogue. The purpose of the present research was to examine how business encounters define and delineate the concept of culture because the researcher is sure that in business communication there are a lot of communicative difficulties due to different cultures. The present research has established that we communicate the way we do because we are raised in a particular culture and learn its language, rules, and norms. The multicultural makeup of organizations is one of the main causes of the communication breakdowns that today's organizations are experiencing. The analysis of the survey revealed several misunderstandings regarding the notion of culture. However, even though we all know to which culture belong, definition of the word has been difficult (Katan 1999:16). 'Definition of the culture usually turn on postulations of structures of contents and values of groups, generally nation-sized' (Menezes de Souza 2006: 107). For instance, Geertz (1973) takes a semiotic approach that defines culture as having to do with creating meaning through communication. Culture is understood, in this context, as collectively held set of attributes, which is dynamic and changing over time. Cultural awareness or cultural intelligence is increasingly being viewed as a critical skill in securing success in multicultural environment. With more people from culturally diverse backgrounds meeting within the business environment, clear and effective communication is necessary between them. Although in many cases a common language may exist, usually English, culture can and does still cause problems. Having an understanding of culture differences is a must for all organizations in the UAE.

After the first questions regarding their demographic characteristics we start analyzing the rest of the questions with their respective answers: in the first question was asked to the participants to rate in a scale from 1 to 8 where they could see mostly cultural differences in the business context in the UAE, where 1 was the most important difference and 8 the least. The answers were very different which emphasized the fact 
the participants didn't have the right knowledge about the differences. For example, most of them didn't know that greetings were different among different cultures. The eating habits got in many cases the most important difference, since most of the time, participants were eating together and they could see that food was different and they usually talked about their eating habits with their colleagues. Also the language was another option considered a very important difference, but was not considered a very big problem of communication since English language was used more often. When asked about the language, they admitted that many times could not understand the Indian accent, particularly in a phone conversation. The participants who are Arabs admitted they used more Arabic language in phone conversations particularly when talking with locals, but they felt very comfortable in speaking English as well. The way of dressing was something very easy for the participants to understand it as a difference. Most of the Arab women used the abaya at work, while the others were obligated to follow some rules in dressing (no short sleeves, or skirt above the knee, etc.) Many of them didn't know that Americans were very informal culture and the rest of the nationalities working in the organization were part of culture were formality was a value. Some of the participants didn't know that the value of time was also different in different cultures. They thought it was an excuse that some of their colleagues used when late at work. When we explained that the usage of time is different among cultures where for example in Arab culture is not an important value, and people use a lot the word Inshallah which refers to not a specific deadline, they could understand and were amused. We also explained them that the Americans value the usage of time, because they hate wasting it, and the participants could give examples of how many times their American managers had told them to be always on time at work. In addition, they didn't know that working individually or in team was a different value in different cultures. After we explained them, they could understand the reason why the Americans preferred to work individually and Arabs and Indians loved more teamwork. While they didn't understand the reason why it is a difference the explicit and implicit way of communication, they could not see a difference. Actually this is the truth because the implicit way of communication is more common in the Japanese culture and none from the participants was Japanese. In the next questions the participants were asked if the company they were working on organized cross-cultural trainings. All the participants of both companies answered, no. the knowledge they knew was only from the internet or relations they had of other cultures living in the UAE. The other question: Cultural differences can cause problems in business communication between people with different cultural backgrounds -121 respondents chose the answer strongly agree. The others thought that culture differences were not a problem in business. The other question: Cultural adaptability is important in business communication in the global workplace - 183 respondents agreed that people could prevent cross-cultural conflicts by learning about cultures that they come in contact with and so they can behave in a more flexible way in the interactions. In the other question: Cultural differences have a negative effect on the performance of jobs -123 respondents agreed and the rest disagreed. Answers and comments to the other question: Stereotypes in culture influence business communication - they all agreed that they were influenced by the stereotypes in their daily life and in the business. It was true even for those who were working in UAE for more than 2 years. (i.e. 'The Americans are sociable, open and friendly', 'The British are cold and reserved'). Consequently, in a way, old stereotypes still are alive even though there are a lot of new symbols, the changing reality (including contacts and working together with representatives of diverse culture).

I would like to emphasize that all the participants accept that diversity is increasing in the world and in the UAE. Therefore workforce has to be prepared in this multicultural working environment. But it is difficult to change attitudes because they fulfil important cognitive and sociological functions. Our hypothesis was that the participants involved in the research would show evidence of more positive multicultural knowledge on intercultural business relations, tolerance and self-esteem. But most of respondents seemed not to know or not to be sure that communication at a multicultural workplace includes not only linguistic elements (grammar, syntax, pronunciation) but also interactional competence (turn taking, opening or closing a conversation etc.), as well as the sociocultural aspects of speakers. The only way to overcome the problems is by recognizing the differences and similarities in communication between people with the different cultural backgrounds. Success in working with colleagues from different culture is not easy goal. In order to connect, the colleagues at a multicultural company have to communicate effectively and they can do this in an atmosphere of mutual respect. The survey proved that cross-cultural trainings are necessary to held. $100 \%$ of respondents said that cross-cultural trainings had not been organized at their companies and they added that they would definitely participate if they will organize in the future. Trainings should help them understand the underlying cultural values that drive behavior - first they can understand their own cultural background and then other people's. Every respondent has not understood that intercultural approach to business communication seeks to interpret the way that members of a group represent themselves during the communication process. Intercultural communication trainings should help them to accept that there are external behaviors: language, gestures, habits; products: literature, folklore, art, music, artefacts and internal (ideas: beliefs, values, institutions) levels (Robinson 1998: 7-13) relating to culture. 


\section{CONCLUSION}

The interest in the study of business communication has grown tremendously during the past several years. The present paper is one step of an ongoing research comprising linguists, economists and experts in communication who would like to study several aspects of the recent phenomenon known as 'intercultural approach to business communication' from a multi-disciplinary point of view. It is true that the rich heritage of diverse cultures is a valuable resource to be protected, and that a major educational effort is needed to convert the diversity from a barrier to communication into a source of mutual enrichment and understanding (Clyne 1992). In order to communicate in business, to obtain knowledge of practice of the strategies, it is not enough to learn the words and the grammar; it also involves being able to handle the language as the vehicle or the medium of a culture. Intercultural and linguacultural competencies (FitzGerald 2003: 170-203) should be developed in order to communicate very effectively in multicultural environment. Communicative behavior is believed to be strongly influenced by cultural value systems (FitzGerald 2003: 21). Samovar and Porter (1991:108) claim that 'in the study of human interaction, it is important to look at cultural values, but in the study of intercultural communication it is crucial'. In their comments the respondents highlighted that in the 21st century globally employable graduates are needed who do possess intercultural empathy. This is already an urgent need in the business world where multicultural encounters have become a common practice. Therefore a need of cross-cultural training is a must in all companies.

\section{RECCOMENDATIONS}

The study is a result of the city of Abu Dhabi and two multinational companies. In the near future I will try to expand the research in the city of Dubai as well, since it is more multicultural than Abu Dhabi with more western nationalities. In addition, as understood from my research, most of respondents are in the country between 2 and 5 years. It is known that people who come to live in a new country may come across the culture shock. Culture shock is a common phenomenon and is more than simply being unfamiliar with social norms or experiencing new foods and it tends to impact people even after they've become familiar with and comfortable in the new culture. Culture shock generally moves through four different phases: honeymoon, frustration, adjustment and acceptance. While individuals experience these phases differently and the impact and order of each stage varies widely, they do provide a guideline of how we adapt and cope with new cultures. I believe respondents who live in the UAE for more than 5 years may be close to the acceptance phase and the results of the study would be different, since we may find more understanding of the culture among respondents.

\section{REFERENCE LIST}

Ellwood, W. (2001). No-Nonsense Guide to Globalization. London: Verso Publishing.

FitzGerald, H. (2003). How different are we? Spoken Discourse in Intercultural Communication. Clevedon: Multilingual Matters Ltd.

Geertz, C. (1974). The Interpretation of Cultures. New York: Basic Books.

Katan, D. (1999). Translating Cultures. Manchester: St. Jerome Publishing.

Lin, C. Y. (1999). A Comparison of Perceptions about Business Ethics in Four Countries. Journal of Psychology, 133(6), 641-655.

Menezes de Souza, L.M.T. (2006). Language, Culture, Multimodality and Dialogic Emergence. Language and Intercultural Communication, 6 (2), 107-112.

Palazzo, B. (2002). U.S.-American and German Business Ethics: An Intercultural Comparison. Journal of Business Ethics, 41(3), 195-216.

Robertson, R. (1992). Globalization. Social Theory and Global Culture. London: Sage.

Robinson, G. (1988). Cross-cultural Understanding. Hemel Hempstead, Hertfordshire: Prentice Hall International.

Samovar, L. A., Porter, R. E. (1991). Communication between Cultures. Belmont, CA: Wadsworth.

Scollon, R., Wong Scollon, S. (2001). Intercultural Communication, A Discourse Approach. Blackwell Publishing.

Sims, R. L. (2009). Collective versus Individualist National Cultures. Comparing Taiwan and U.S. Employee Attitudes toward Unethical Business Practices. Business \& Society. 2009. vol. 48. 